\title{
Is there an association between the home food environment, the local food shopping environment and children's fruit and vegetable intake? Results from the Dutch INPACT study
}

\author{
Wilke JC van Ansem ${ }^{1, *}$, Carola TM Schrijvers ${ }^{1}$, Gerda Rodenburg ${ }^{1,2}$ and \\ Dike van de Mheen ${ }^{1,2}$ \\ 'IVO Addiction Research Institute, Heemraadssingel 194, 3021 DM Rotterdam, the Netherlands: ${ }^{2}$ Erasmus \\ Medical Centre, Rotterdam, the Netherlands
}

Submitted 15 December 2011: Final revision received 10 May 2012: Accepted 17 June 2012: First published online 8 August 2012

\begin{abstract}
Objective: To examine: (i) the association between home availability of fruit and vegetables and children's fruit and vegetable intake; (ii) the association between parental perception of the local food shopping environment and the home availability of fruit and vegetables; and (iii) whether the home availability of fruit and vegetables mediates the association between parental perception of the local food environment and children's fruit and vegetable consumption.

Design: Cross-sectional study.

Setting: A total of ninety-one primary schools in the Netherlands.

Subjects: In total 1501 primary caregivers completed a questionnaire to measure children's fruit and vegetable consumption, home availability of fruit and vegetables, parental perceptions of the local food shopping environment (price, quality and availability), the child's socio-economic status, the child's ethnicity and maternal height and weight.

Results: The home availability of fruit and vegetables was positively associated with children's fruit and vegetable intake $(P<0 \cdot 01$ and $P<0 \cdot 001$, respectively). Negative parental perceptions of the local food shopping environment were associated with less fruit available at home $(P<0.05, P<0.01$ and $P<0.05$ for price, quality and availability of fruit, respectively). No significant associations were found between parental perception of the local food shopping environment and children's fruit and vegetable consumption. We found no evidence that home availability of fruit and vegetables mediates the association between parental perception of the local food environment and children's fruit and vegetable intake. Conclusions: Interventions focusing on improving the home availability of fruit and vegetables may help to increase children's fruit and vegetable consumption. However, more data are required on factors influencing the home availability of fruit and vegetables.
\end{abstract}

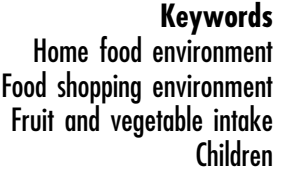

Keywords Food shopping environment Children
The beneficial effects on health of fruit and vegetables are well documented. Fruit and vegetables are rich in vitamins and fibre and can protect against CVD, some types of cancer and obesity ${ }^{(1-3)}$. There is also evidence that fruit and vegetable consumption in childhood protects against respiratory diseases ${ }^{(4-6)}$. It is also reported that fruit consumption in childhood reduces the risk of cancer in adulthood ${ }^{(7)}$. Because of the beneficial effects of fruit and vegetables, many countries (including the Netherlands) have dietary recommendation guidelines for fruit and vegetable intake for adults and children. For example, the US Department of Agriculture recommends a daily intake of $1 \frac{1}{2}$ cups of fruit and 2 cups of vegetables for children aged $9-13$ years $^{(8)}$. The WHO and FAO recommend daily intake of $400 \mathrm{~g}$ of both fruit and vegetables ${ }^{(9)}$. The Dutch dietary guidelines for children aged 9-13 years recommend to consume at least two pieces of fruit and $150 \mathrm{~g}$ of vegetables daily ${ }^{(10)}$. However, the majority of children in the Netherlands, as in many other countries, do not consume these recommended amounts $^{(11-14)}$. This stresses the need to develop interventions aimed at promoting increased intake of fruit and vegetables among children. In order to develop such interventions, more knowledge on the determinants of their fruit and vegetable intake is required.

Several studies have examined the correlates of children's nutritional behaviour. Traditionally, these focused on individual-level correlates such as knowledge, 


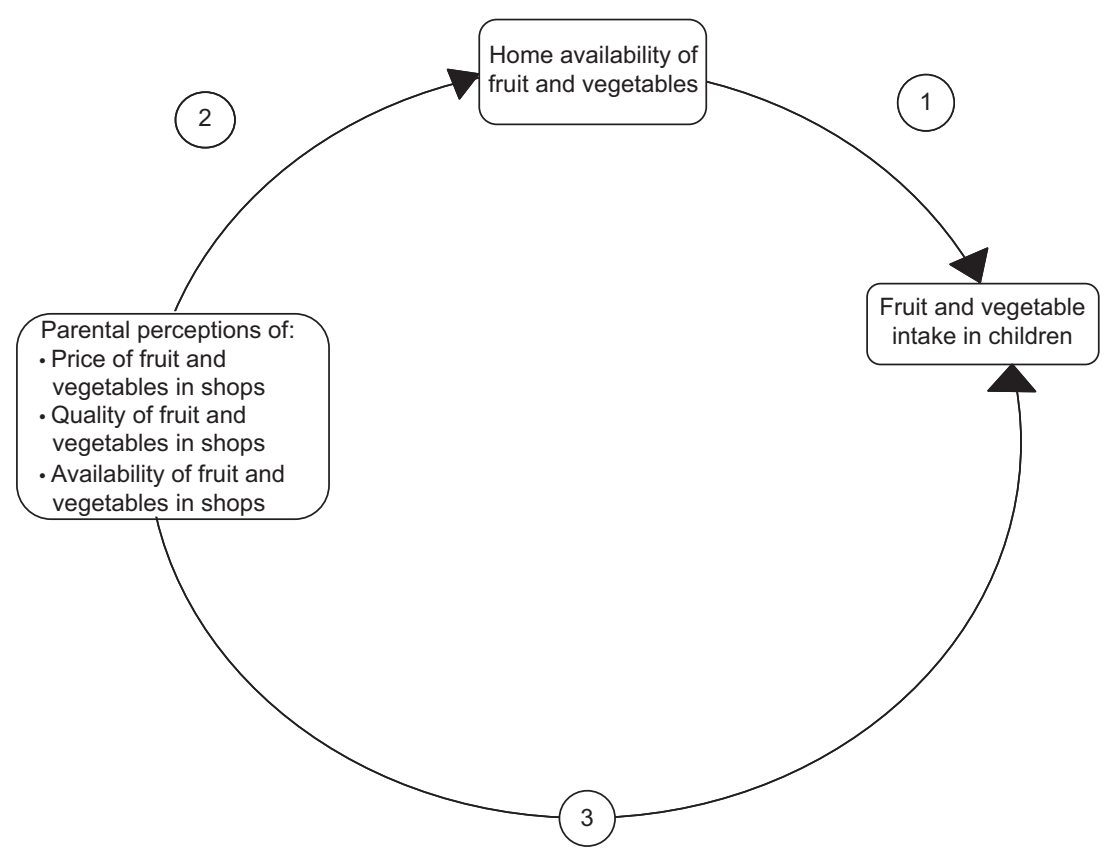

Fig. 1 Conceptual research model used in the present study

attitudes, beliefs and taste preference. In recent years, ecological models and frameworks have highlighted the need to consider environmental factors in relation to nutritional behaviour ${ }^{(15-18)}$. For children, the home food environment, the local food shopping environment and the school food environment are important settings in which their nutritional behaviour takes place. Most research on environmental correlates of children's fruit and vegetable consumption have included the home food environment ${ }^{(19-23)}$ and the local food shopping environment ${ }^{(24-26)}$.

The home food environment is a broad concept and includes home availability and accessibility of food, parental role modelling, parenting feeding styles and family food rules. Several literature reviews have concluded that elements of the home food environment are associated with children's fruit and vegetable intake. One of the elements of the home food environment that has been strongly associated with children's fruit and vegetable consumption is food availability at home. Children eat more fruit and vegetables when fruit and vegetables are available in their homes ${ }^{(21-23)}$.

The local food shopping environment includes measures of proximity and density of food outlets and availability, quality and price of food in shops. Research on the association between aspects of the local food shopping environment and children's fruit and vegetable intake is limited ${ }^{(24-26)}$; most studies in this field were performed among adults. Some studies among children and adolescents have been performed, but with inconsistent findings. For example, one study found that children with more fast-food restaurants and convenience stores close to home consumed lower amounts of fruit and vegetables; it was also found that children who lived further away from a supermarket or a fast-food store consumed more vegetables ${ }^{(24)}$. Another study found that children who lived further away from supermarkets consumed more fruit and vegetables; however, that study found that a higher density of supermarkets in a neighbourhood was related to increased vegetable consumption ${ }^{(25)}$. In a more recent study, no association was found between the proximity of food outlets and children's fruit and vegetable consumption ${ }^{(26)}$.

As stated before, most research on environmental determinants of children's fruit and vegetable intake focuses mainly on either the home food environment or the local food shopping environment. Few studies have focused on both the home food environment and the local food shopping environment. It is likely that the local food shopping environment influences the home food environment, especially the home availability of fruit and vegetables. Therefore, the main aim of the present study was to examine both direct and indirect pathways between the local food shopping environment and children's fruit and vegetable intake (Fig. 1; conceptual research model).

The local food shopping environment can be measured objectively (e.g. objective assessment via geographic information systems) or subjectively (e.g. perceptions about characteristics of the local food shopping environment). Objectively measured environmental determinants neglect the perception of respondents about their environments. This perception is likely to be more important for behavioural choices, such as fruit and vegetable consumption, 
than objectively measured aspects of the local food shopping environment ${ }^{(27)}$. The present study is, as far as we know, the first one which examines subjectively measured factors of the local food shopping environment in relation to children's fruit and vegetable consumption.

In the current paper we examine: (i) the association between home availability of fruit and vegetables and children's fruit and vegetables intake; (ii) the association between parental perception of the local food shopping environment and the home availability of fruit and vegetables; and (iii) whether the home availability of fruit and vegetables mediates the association between parental perception of the local food shopping environment and children's fruit and vegetable intake.

\section{Methods}

\section{Population and design}

INPACT is the acronym for IVO Nutrition Physical Activity Child cohorT. INPACT is a longitudinal Dutch study among 8-12-year-old children and their parents. The aim of the study is to examine environmental determinants of children's dietary behaviour and physical activity. In 2008 the INPACT study started among grade 3 children (age 8 years); the subsequent waves of data collection took place in 2009 (second wave) and 2010 (third wave). Participants were recruited through primary schools in the southern part of the Netherlands (Eindhoven and surroundings). All general primary schools ( $n$ 265) in this area were invited to participate in the study by the municipal health services; finally, ninety-one schools $(34.3 \%)$ took part.

The response rate from rural and urban schools was equal. A sample of 1844 primary caregivers and their children $(62.5 \%)$ gave informed consent.

The INPACT study was approved by the Ethical Committee of Erasmus Medical Centre, Rotterdam.

The present study was based on the data collection of the third wave (2010) of the INPACT study, which is the only wave that collected data on the local food shopping environment. All data presented herein were measured by means of a questionnaire. The primary caregiver filled in a questionnaire at home; 1501 (81.4\%) primary caregivers, of whom $91.8 \%$ ( $n$ 1378) were the biological mother, completed the questionnaire in 2010.

\section{Measures}

\section{Fruit and vegetable intake}

Usual fruit and vegetable intake was measured with a questionnaire that was based on validated $\mathrm{FFQ}^{(28,29)}$. The primary caregiver of the child was asked how often his/her child usually eats: (i) fruit (fresh or canned fruit); (ii) cooked, fried, steamed or otherwise heated vegetables; and (iii) salad or other raw vegetables. Answering categories ranged from 'none or less than one day a week' to
'7 days a week'. The primary caregiver was also asked how many servings of fruit and vegetables his/her child usually eats. For fruit, answer categories ranged from ' 0 pieces a day' to 'more than three pieces a day' in increments of half a piece of fruit. Reported fruit consumption of 'more than three pieces a day' ( $n$ 12) was recoded as 'four pieces a day'. For vegetables, answer categories ranged from '0 serving spoons' to 'more than four serving spoons a day' in increments of half a serving spoon. Reported vegetable consumption of 'more than four serving spoons a day' ( $n$ 22) was recoded as 'five serving spoons'. One serving spoon was equivalent to $50 \mathrm{~g}$ of vegetables, which is a standard serving of vegetables in the Netherlands. Total fruit and vegetable intake was calculated for each child by multiplying consumption frequency and serving portions. Total fruit and vegetable intake was dichotomized to be consistent with the current Dutch guidelines for fruit ( $<2$ pieces $/ \mathrm{d}, \geq 2$ pieces $/ \mathrm{d}$ ) and vegetables $(<150 \mathrm{~g} / \mathrm{d}$, $\geq 150 \mathrm{~g} / \mathrm{d}$ ) for children in this age group.

\section{Home availability fruit and vegetables}

The availability of fruit and vegetables at home was measured with a questionnaire based on the validated Home Environment Survey ${ }^{(30)}$. The primary caregiver was asked about the availability of fruit and vegetables in their home, separately. Response categories were 'yes, always', 'yes, usually', 'sometimes', 'no, usually not' and 'no, never'. Due to limited variability of these variables, we dichotomized both variables into 'always' ('yes, always') and 'not always' ('yes, usually'; 'sometimes'; 'no, usually not'; 'no, never').

\section{Local food shopping environment}

We measured perceptions of the local food shopping environment with regard to: (i) price of fruit and vegetables; (ii) quality of fruit and vegetables; and (iii) availability of fruit and vegetables in the shops. Parental perceptions of these features were measured with three statements ('Fruit is expensive'; 'Quality of fruit is bad'; 'Availability of fruit in the shops is limited'). For vegetables the same statements were used. Answering categories for these statements were dichotomous: 'agree' or 'disagree'. The statements about the local food shopping environment have been used in another Dutch study ${ }^{(31)}$ and were based on the results from a focus group of Dutch adults ${ }^{(32)}$ and a literature review, to identify salient environmental determinants of fruit and vegetable consumption.

To avoid misunderstanding about the meaning of 'the local food shopping environment', we described in the questionnaire that the above-mentioned statements refer explicitly to food shopping outlets where participants usually go to purchase their fruit or vegetables.

\section{Potential confounders}

Child's age, child's ethnicity, child's socio-economic status (SES), child's BMI and maternal BMI were assessed as potential confounders. 
Child's age was calculated from the date of birth and the date of measurement. Child's ethnicity was categorized into: 'native Dutch' (both parents were born in the Netherlands), 'Western immigrant' (at least one of the parents was not born in the Netherlands, but inside Europe (including former Yugoslavia and Soviet Union), North America, Oceania, Indonesia or Japan) and 'nonWestern immigrant' (at least one of the parents was born in Turkey, Africa, Latin America or Asia).

Maternal educational level was used to measure child's SES. Maternal educational level was categorized into three groups: 'low' (primary school and lower secondary education), 'intermediate' (intermediate vocational education, higher secondary school and pre-university education) and 'high' (higher vocational education and university).

\section{$B M I$}

Children's weight and height were measured in underwear without shoes to the nearest $0 \cdot 1 \mathrm{~cm}$ and $0 \cdot 1 \mathrm{~kg}$; the measurements were made by trained research assistants. Weight and height were used to calculate the children's BMI; subsequently, children's BMI was categorized as 'underweight', 'normal weight' and 'overweight/obese'(33). Overweight and obesity were pooled into one category due to the small number of obese children. Maternal BMI was calculated from self-reported data of weight and height. Maternal BMI was categorized into underweight (BMI < $\left.18 \cdot 50 \mathrm{~kg} / \mathrm{m}^{2}\right)$, normal weight $\left(\mathrm{BMI}=18 \cdot 50-24 \cdot 99 \mathrm{~kg} / \mathrm{m}^{2}\right)$ and overweight/obese (BMI $\left.\geq 25 \cdot 00 \mathrm{~kg} / \mathrm{m}^{2}\right)$.

\section{Statistical analyses}

Descriptive analyses were performed to describe the distribution of child age, child gender, child ethnicity, child BMI, maternal BMI and maternal educational level, children's consumption of fruit and vegetables, home availability of fruit and vegetables and parental perceptions of the local food environment.

The Pearson $\chi^{2}$ test was used to explore possible confounders (child age, child gender, child ethnicity, child BMI, maternal BMI, child SES). Based on the results of the Pearson $\chi^{2}$ test, all analyses were controlled for ethnicity, child BMI and child SES.

We used the four-step approach of Baron and Kenny to test whether home availability of fruit and vegetables mediated the association between the local food shopping environment and children's fruit and vegetable consumption ${ }^{(34)}$. According to Baron and Kenny, a mediator has to be associated with the predicted variable and with the outcome variable, and the predicted variable has to be associated with the outcome variable (steps 1-3 of the approach). When the associations in steps 1-3 are all significant, the criteria for mediation are met. Subsequently, step 4 assesses whether it is full mediation or partial mediation. To test if the criteria for mediation were met, several multivariate logistic regression
Table 1 Characteristics of the study population: 8-12-year-old children and their parents, Dutch INPACT study, 2010

\begin{tabular}{lrr}
\hline Characteristic & $n$ & $\%$ \\
\hline Child's age (years) & & \\
9 & 45 & $3 \cdot 0$ \\
10 & 1172 & $78 \cdot 4$ \\
11 & 268 & $17 \cdot 9$ \\
$>12$ & 9 & $0 \cdot 6$ \\
Child's gender & 757 & $50 \cdot 5$ \\
Boy & 742 & $49 \cdot 5$ \\
Girl & & \\
Child's ethnicity & 1288 & $86 \cdot 0$ \\
Native Dutch & 121 & $8 \cdot 1$ \\
Western immigrant & 89 & $5 \cdot 9$ \\
Non-Western immigrant & & \\
Child's BMl & 116 & $7 \cdot 0$ \\
Underweight & 1281 & $77 \cdot 7$ \\
Normal weight & 251 & $15 \cdot 2$ \\
Overweight/obese & & \\
Maternal BMl & 19 & $1 \cdot 3$ \\
Underweight & 953 & $65 \cdot 7$ \\
Normal weight & 479 & $33 \cdot 0$ \\
$\quad$ Overweight/obese & & \\
Maternal educational level & 380 & $22 \cdot 1$ \\
Low & 791 & $46 \cdot 1$ \\
Intermediate & 545 & $31 \cdot 8$ \\
High & & \\
\hline
\end{tabular}

models were computed to assess the associations between (Fig. 1):

1. home availability of fruit and vegetables (possible mediator) and children's fruit and vegetable consumption (outcome variable);

2. parental perception of the local food shopping environment (predicted variable) and home availability of fruit and vegetables (possible mediator); and

3. parental perception of the local food shopping environment (predicted variable) and children's fruit and vegetable consumption (outcome variable).

All analyses were performed with the statistical software package IBM SPSS statistics 19. Due to missing values, the numbers of participants included in the analyses differ for each model that was computed.

\section{Results}

\section{Participant's characteristics}

Table 1 presents some characteristics of the study population. Mean age of the children was $10 \cdot 2$ years, most were native Dutch $(86 \cdot 0 \%)$ and $15 \cdot 2 \%$ were overweight/obese. The majority of the mothers had an intermediate level of education and $33.0 \%$ of them were overweight/obese.

\section{Associations between bome availability of fruit and vegetables and children's fruit and vegetable consumption}

Most children did not consume the recommended amount of fruit and vegetables: $87 \cdot 4 \%$ of the children consumed 
Table 2 Associations between home availability of fruit and vegetables and children's fruit and vegetable consumption, Dutch INPACT study, 2010

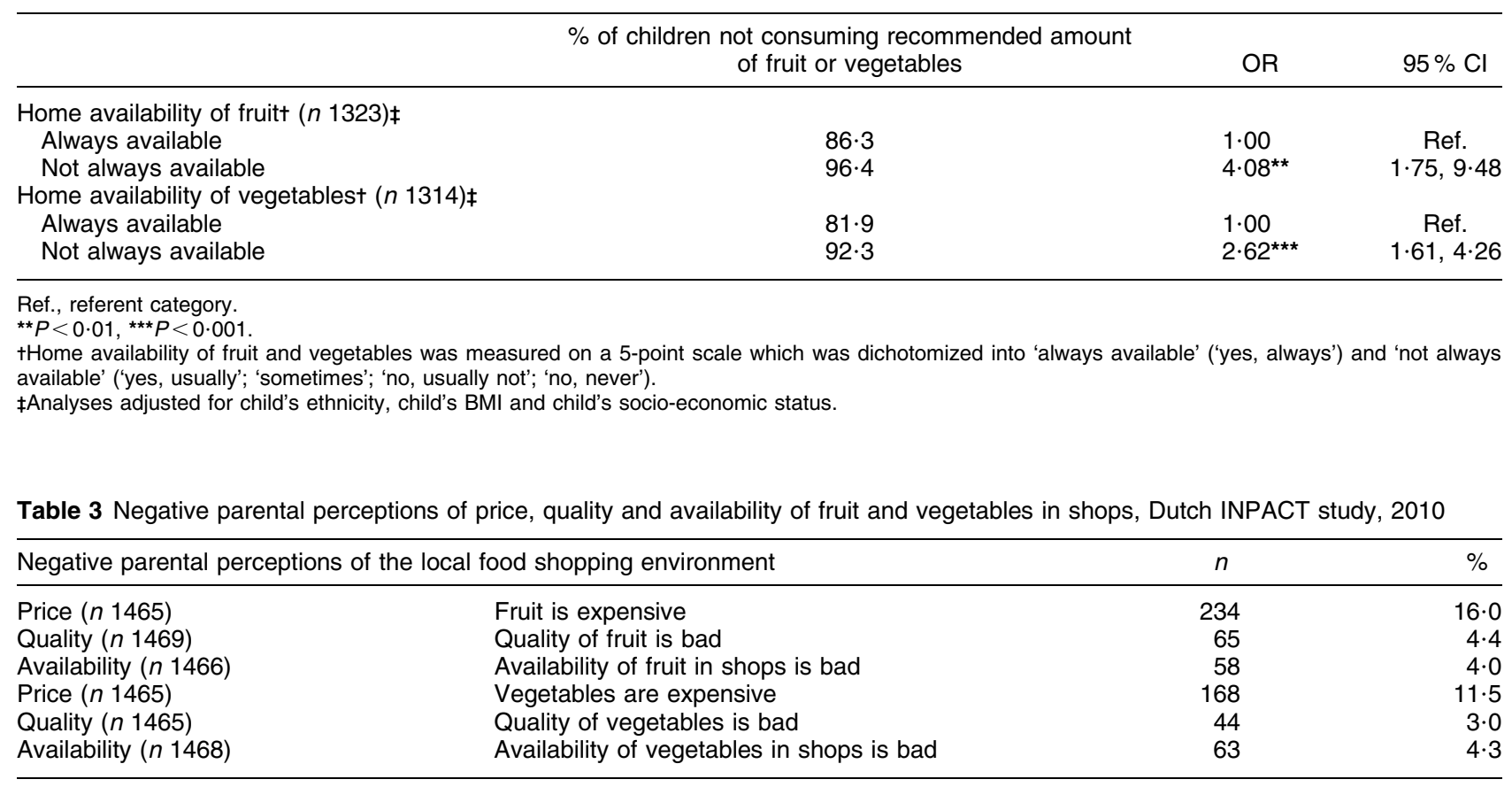

$<2$ pieces fruit/d and $83 \cdot 8 \%$ consumed $<150 \mathrm{~g}$ vegetables/d. The majority of the children had fruit $(88 \cdot 8 \%)$ or vegetables $(80.8 \%)$ always available in their homes. Table 2 shows the association between the home availability of fruit and vegetables and children's fruit and vegetable consumption. Children who lived in a household where fruit was not always available were less likely to consume the recommended amount of fruit $(\mathrm{OR}=4 \cdot 08,95 \% \mathrm{CI} 1 \cdot 75,9 \cdot 48, P<0 \cdot 01)$. For vegetables, a similar association was found between home availability and children's consumption (OR $=2 \cdot 62$, 95\% $1 \cdot 61,4 \cdot 26, P<0 \cdot 001)$.

\section{Associations between parental perception of the local food shopping environment and bome availability of fruit and vegetables}

Table 3 provides data on parental perceptions of the local food environment. A minority of parents had a negative perception about the price of fruit or vegetables (fruit: $16 \cdot 0 \%$, vegetables: $11.5 \%$ ), quality of fruit or vegetables (fruit: $4 \cdot 4 \%$, vegetables: $3 \cdot 0 \%$ ) and the availability of fruit or vegetables in shops (fruit: $4 \cdot 0 \%$, vegetables: $4 \cdot 3 \%$ ). Table 4 presents data on the association between parental perceptions about the price, quality and availability of fruit and vegetables in shops and the home availability of fruit and vegetables. Children of parents with negative perceptions of price, quality and availability were more likely to not always have fruit available in their homes (price: $O R=1 \cdot 56,95 \%$ CI $1 \cdot 02,2 \cdot 40$, $P<0 \cdot 05$; quality: OR $=3 \cdot 03,95 \%$ CI $1 \cdot 59,5 \cdot 77, P<0 \cdot 01$; availability: $\mathrm{OR}=2 \cdot 79 ; \quad 95 \%$ CI $1 \cdot 38,5 \cdot 64, P<0 \cdot 05)$.
For vegetables, no significant association was found between parental perceptions concerning the price, quality and availability in shops and the availability of vegetables at home.

\section{Associations between parental perception of the local food shopping environment and children's fruit and vegetable consumption}

Table 5 presents data on the association between parental perceptions of the price, quality and availability of fruit and vegetables in shops and children's fruit and vegetable consumption. No aspect of the local food shopping environment was associated with children's fruit and vegetable consumption.

\section{Mediation of the bome food environment on the association between parental perception of the local food shopping environment and children's fruit and vegetable consumption}

We found no association between parental perception of the local food shopping environment and children's fruit and vegetable consumption, and no association between parental perception of the local food shopping environment and the home availability of vegetables. Therefore, the criteria for mediation were not met for both the association between parental perception of the local food shopping environment and children's fruit consumption and the association between parental perception of the local food shopping environment and children's vegetable consumption. 
Table 4 Associations between parental perceptions of price, quality and availability of fruit and vegetables and the availability of fruit and vegetables at home, Dutch INPACT study, 2010

\begin{tabular}{|c|c|c|c|}
\hline & $\begin{array}{c}\% \text { of children who do not always have fruit or } \\
\text { vegetables available at homet }\end{array}$ & OR & $95 \% \mathrm{Cl}$ \\
\hline \multicolumn{4}{|l|}{ Fruitł } \\
\hline \multicolumn{4}{|l|}{ Price $(n$ 1303) } \\
\hline Fruit is expensive & $15 \cdot 0$ & $1 \cdot 56^{\star}$ & \multirow{2}{*}{$\begin{array}{l}1 \cdot 02,2 \cdot 40 \\
\text { Ref. }\end{array}$} \\
\hline Fruit is not expensive & $10 \cdot 5$ & $1 \cdot 00$ & \\
\hline \multicolumn{4}{|l|}{ Quality ( $n$ 1309) } \\
\hline Quality of fruit in shops is bad & $23 \cdot 4$ & $3 \cdot 03^{\star \star}$ & \multirow{2}{*}{$\begin{array}{l}1 \cdot 59,5 \cdot 77 \\
\text { Ref. }\end{array}$} \\
\hline Quality of fruit in shops is not bad & $10 \cdot 5$ & 1.00 & \\
\hline \multicolumn{4}{|l|}{ Availability ( $n$ 1306) } \\
\hline Availability of fruit in shops is limited & $20 \cdot 7$ & $2 \cdot 79^{\star}$ & \multirow{2}{*}{$\begin{array}{l}1 \cdot 38,5 \cdot 64 \\
\text { Ref. }\end{array}$} \\
\hline Availability of fruit in shops is not limited & $10 \cdot 9$ & $1 \cdot 00$ & \\
\hline \multicolumn{4}{|l|}{ Vegetables $\ddagger$} \\
\hline \multicolumn{4}{|l|}{ Price $(n 1294)$} \\
\hline Vegetables are expensive & $17 \cdot 4$ & 0.93 & \multirow{2}{*}{$\begin{array}{l}0 \cdot 60,1 \cdot 44 \\
\text { Ref. }\end{array}$} \\
\hline Vegetables are not expensive & $19 \cdot 8$ & $1 \cdot 00$ & \\
\hline \multicolumn{4}{|l|}{ Quality ( $n$ 1295) } \\
\hline Quality of vegetables in shops is bad & $22 \cdot 7$ & $1 \cdot 34$ & \multirow{2}{*}{$\begin{array}{l}0 \cdot 65,2 \cdot 79 \\
\text { Ref. }\end{array}$} \\
\hline Quality of vegetables in shops is not bad & $19 \cdot 3$ & $1 \cdot 00$ & \\
\hline \multicolumn{4}{|l|}{ Availability ( $n$ 1298) } \\
\hline Availability of vegetables in shops is limited & $23 \cdot 0$ & $1 \cdot 63$ & \multirow{2}{*}{$\begin{array}{l}0.89,3.09 \\
\text { Ref. }\end{array}$} \\
\hline Availability of vegetables in shops is not limited & $19 \cdot 2$ & 1.00 & \\
\hline
\end{tabular}

Ref., referent category.

${ }^{*} P<0.05,{ }^{\star \star} P<0.01$.

tHome availability of fruit and vegetables was measured on a 5-point scale which was dichotomized into 'always available' ('yes, always') and 'not always available' ('yes, usually'; 'sometimes'; 'no, usually not'; 'no, never').

$\ddagger$ Analyses adjusted for child’s ethnicity, child’s BMI and child’s socio-economic status.

Table 5 Associations between parental perceptions of price, quality and availability of fruit and vegetables and children's fruit and vegetable consumption, Dutch INPACT study, 2010

\begin{tabular}{|c|c|c|c|}
\hline & $\begin{array}{l}\% \text { of children not consuming the recommended } \\
\text { amount of fruit or vegetables }\end{array}$ & OR & $95 \% \mathrm{Cl}$ \\
\hline \multicolumn{4}{|l|}{ Fruitt } \\
\hline \multicolumn{4}{|l|}{ Price $(n 1300)$} \\
\hline Fruit is expensive & $87 \cdot 1$ & $0 \cdot 89$ & $0.57,1 \cdot 40$ \\
\hline Fruit is not expensive & $87 \cdot 7$ & $1 \cdot 00$ & Ref. \\
\hline \multicolumn{4}{|l|}{ Quality $(n 1306)$} \\
\hline Quality of fruit in shops is bad & $89 \cdot 2$ & 0.67 & $0 \cdot 26,1 \cdot 72$ \\
\hline Quality of fruit in shops is not bad & $87 \cdot 5$ & $1 \cdot 00$ & Ref. \\
\hline \multicolumn{4}{|l|}{ Availability $(n 1303)$} \\
\hline Availability of fruit in shops is limited & $89 \cdot 7$ & $0 \cdot 36$ & $0 \cdot 11,1 \cdot 20$ \\
\hline Availability of fruit in shops is not limited & $87 \cdot 4$ & $1 \cdot 00$ & Ref. \\
\hline \multicolumn{4}{|l|}{ Vegetablest } \\
\hline \multicolumn{4}{|l|}{ Price $(n$ 1299) } \\
\hline Vegetables are expensive & $83 \cdot 3$ & $1 \cdot 01$ & $0.64,1.59$ \\
\hline Vegetables are not expensive & $83 \cdot 8$ & $1 \cdot 00$ & Ref. \\
\hline \multicolumn{4}{|l|}{ Quality ( $n$ 1301) } \\
\hline Quality of vegetables in shops is bad & $90 \cdot 9$ & 0.54 & $0.19,1.56$ \\
\hline Quality of vegetables in shops is not bad & $83 \cdot 5$ & $1 \cdot 00$ & Ref. \\
\hline \multicolumn{4}{|l|}{ Availability ( $n$ 1304) } \\
\hline Availability of vegetables in shops is limited & $82 \cdot 5$ & $0 \cdot 77$ & $0.79,1.67$ \\
\hline Availability of vegetables in shops is not limited & $83 \cdot 7$ & $1 \cdot 00$ & Ref. \\
\hline
\end{tabular}

Ref., referent category.

tAnalyses adjusted for child's ethnicity, child's BMI and child's socio-economic status.

\section{Discussion}

The present study is one of the first to examine associations between parental perception of the local food shopping environment, the home food environment and children's fruit and vegetable intake. It was found that children who lived in a household where fruit and/or vegetables were not always available were less likely to consume the recommended daily amount of fruit or vegetables. Furthermore, negative parental perceptions of the local food shopping environment were associated with a reduced availability of fruit at home. No associations were found 
between parental perception of the local food shopping environment and children's fruit and vegetable intake. Finally, home availability of fruit and vegetables did not mediate the association between parental perception of the local food shopping environment and children's fruit and vegetable consumption.

The finding that home availability of fruit and vegetables is positively associated with children's fruit and vegetable consumption is in line with earlier studies ${ }^{(35-37)}$. Several reviews have concluded that home availability of fruit and vegetables is an important aspect of the home environment in relation to children's fruit and vegetable intake ${ }^{(21-23)}$.

However, before developing interventions targeting home availability of fruit and vegetables, more knowledge on factors influencing the availability of fruit and vegetables is needed. Few studies have examined determinants of the home availability of fruit and vegetables. The present study investigates the relationship between parental perception of the local food shopping environment and home availability of fruit and vegetables. Our results show that negative perceptions of price, quality and availability of fruit in shops are associated with less fruit being available at home, albeit the associations are weak. Contrary to our expectations, we found no associations between parental perceptions of price, quality and availability of vegetables in shops and the home availability of vegetables. However, because only a very small number of people agreed with the statements about the local food shopping environments, there was insufficient variation of the independent variables. This might explain why we found only a weak association between parental perception of the local food shopping environment and the home availability of fruit and no association between parental perception of the local food shopping environment and the home food environment of vegetables. Another explanation for the different findings between parental perception of the local food shopping environment and fruit and vegetable availability at home may be Dutch dietary habits. Traditionally, Dutch people consume three main meals per day and a snack between the main meals. Vegetables are a part of the dinner (as is fish or meat and rice or pasta), whereas fruit is not generally a part of the main meals. In the Netherlands, fruit is mainly consumed as a kind of snack and is generally seen as 'something extra'. Therefore the purchase of vegetables may not be influenced by perceptions about price, quality and availability, whereas this may be the case for fruit.

The present study examined associations between parental perception about the local food shopping environment and children's fruit and vegetable consumption. For both fruit and vegetables no such association was found. This is unexpected because an association was found between parental perception and the home availability of fruit (Fig. 1; association 2) and a strong association was found between the home availability of fruit and children's fruit consumption (Fig. 1; association 1). This unexpected finding may be due to insufficient variation in either the dependent or the independent variable to detect any association. To get more variation in the data we performed the analyses with fruit and vegetable consumption as a continuous variable; however, these analyses yielded comparable results (data not shown). Unfortunately, it was not possible to increase the variability of the measures of the local food shopping environment because the perceptions were measured on a dichotomous scale.

Besides possible methodological shortcomings of the present study another explanation may be that parental perceptions of the local food shopping environment are too distal to directly influence child behaviour. Other determinants such as preference of food taste, food habits or parental attitude regarding fruit and vegetables may be in the indirect pathway and could be more important in relation to children's fruit and vegetable consumption. Also, other factors acting like mediators (which we did not measure) may have an effect opposite to the direct effect of parental perception of the local food shopping environment and children's fruit and vegetable consumption. The opposite effect of the direct pathway and the indirect pathway can cancel each other out, resulting in a non-significant overall relationship between parental perception of the local food shopping environment and children's fruit and vegetable consumption.

To our knowledge, no other studies have examined the relationship between children's fruit and vegetable intake and subjectively measured environmental determinants. However, studies among adults have examined the perceived local food shopping environment and fruit and vegetable consumption. One Dutch study found that some of the subjectively measured factors of the local food shopping neighbourhood were associated with fruit and vegetable consumption; its finding that the quality and availability of fruit and vegetables in shops was not significantly associated with participants' fruit and vegetable consumption is in line with our results ${ }^{(31)}$. Another study found that perceived greater access to fruit and vegetables was significantly associated with increased fruit and vegetable intake ${ }^{(38)}$, while two other American studies found no significant association between subjectively measured determinants of the local food shopping environment and participants' fruit and vegetable consumption $^{(39,40)}$. However, their results are difficult to compare with ours due to different measures of the local food shopping environment. Furthermore, the urban landscape in the Netherlands differs from that in the USA. The population density in the Netherlands is high and shops are generally close to participants' homes. Due to these differences in landscaping the results of the US studies may be not generalizable to the Netherlands.

The present study has some limitations which may have influenced the results. First, our study has a crosssectional design, which hampers drawing conclusions 
about any causal relationships. Second, only one-third of the schools and $62.5 \%$ of the parents participated in the study. However, the school response rate among urban and rural areas was equal. Furthermore, the consumption of fruit and vegetables and the overweight and obesity prevalence were comparable to national prevalence rates among children ${ }^{(41)}$. Therefore, we think that the results in our study are not biased through selective participation.

A third limitation is the use of parent reports on children's fruit and vegetable consumption instead of child reports. It is still unclear, however, whether child reports or parents report of child fruit consumption are more valid. Two Dutch studies reported low agreement between parent and child report on child fruit and vegetable intake $^{(42,43)}$. However, Tak et al. stated that parents' report could be considered a valid method to measure children's fruit and vegetable intake ${ }^{(42)}$. Nevertheless, parents may respond in a socially desirable way, i.e. they may overestimate home availability of fruit and vegetables and overestimate their children's fruit and vegetable consumption. However, we do not expect that this has significantly influenced our results.

Finally, we used maternal educational level as a measure of SES of the household, instead of household income, due to the high number of missing values on this variable $(31 \cdot 2 \%)$. Several studies emphasize that cost is one of the most important determinants of consumer food choice $^{(44,45)}$. Therefore, household income may be a more appropriate measure of the SES of the household. However, after performing all analyses again with household income as the measure for SES (data not shown), the direction and magnitude of the results were similar to those reported based on maternal educational level.

\section{Conclusions}

In the present study, only $12 \cdot 6 \%$ of the children met the recommendation for fruit consumption and only $16 \cdot 2 \%$ met the recommendation for vegetable consumption. The home availability of fruit and vegetables was strongly associated with children's fruit and vegetable intake. Weaker associations were found for subjectively measured factors of the local food shopping environment and the availability of fruit at home. Interventions focusing on improving the home availability of fruit and vegetables may contribute to an increase of children's fruit and vegetable consumption. However, more knowledge on the factors influencing the home availability of fruit and vegetables is required.

\section{Acknowledgements}

This work was funded by ZonMw, The Netherlands Organization for Health Research and Development (project no. 115100004). There are no conflicts of interest.
W.J.C.v.A., C.T.M.S. and D.v.d.M. were involved in the design of this study. W.J.C.v.A. was responsible for data collection, performed the statistical analyses and drafted the manuscript. C.T.M.S. was the daily supervisor of the project. C.T.M.S. and D.v.d.M. helped with the interpretation of the data. C.T.M.S., D.v.d.M. and G.R. helped draft this article.

\section{References}

1. He FJ, Nowson CA \& MacGregor GA (2006) Fruit and vegetable consumption and stroke: meta-analysis of cohort studies. Lancet 367, 320-326.

2. Johnsen SP (2004) Intake of fruit and vegetables and risk of stroke: an overview. Curr Opin Clin Nutr Metab Care 7, $665-670$

3. World Cancer Research Fund \& American Institute for Cancer Research (2007) Food, Nutrition, Physical Activity and the Prevention of Cancer: A Global Perspective. Washington, DC: AICR.

4. Antova T, Pattenden S, Nikiforov B et al. (2003) Nutrition and respiratory health in children in six Central and Eastern European countries. Thorax 58, 231-236.

5. Farchi S, Forastiere F, Agabiti N et al. (2003) Dietary factors associated with wheezing and allergic rhinitis in children. Eur Respir J 22, 772-780.

6. Forastiere F, Pistelli R, Sestini P et al. (2000) Consumption of fresh fruit rich in vitamin $\mathrm{C}$ and wheezing symptoms in children. SIDRIA Collaborative Group, Italy (Italian Studies on Respiratory Disorders in Children and the Environment). Thorax 55, 283-288.

7. Maynard M, Gunnell D, Emmett P et al. (2003) Fruit, vegetables, and antioxidants in childhood and risk of adult cancer: the Boyd Orr cohort. J Epidemiol Community Health 57, 218-225.

8. US Department of Agriculture \& US Department of Health and Human Services (2010) Dietary Guidelines for Americans, 2010, 7th ed. Washington, DC: USDA.

9. World Health Organization \& Food and Agriculture Organization of the United Nations (2003) Diet, Nutrition and the Prevention of Chronic Diseases. Joint WHO/FAO Expert Consultation. WHO Technical Report Series no. 916. Geneva: WHO.

10. The Netherlands Nutrition Centre Foundation (2011) Richtlijnen Voedselkeuze (Dietary Guidelines). Den Hague: The Netherlands Nutrition Centre Foundation.

11. Diethelm K, Jankovic N, Moreno LA et al. (2012) Food intake of European adolescents in the light of different food-based dietary guidelines: results of the HELENA (Healthy Lifestyle in Europe by Nutrition in Adolescence) Study. Public Health Nutr 15, 386-398.

12. Huybrechts I, Matthys C, Vereecken C et al. (2008) Food intakes by preschool children in Flanders compared with dietary guidelines. Int J Environ Res Public Health 5, 243-257.

13. National Institute for Public Health and the Environment (2007) Dutch National Food Consumption Survey Young Children 2005/2006. Bilthoven: RIVM.

14. World Health Organization (2004) Young People's Health in Context. Health Behavior in School-aged Children (HBSC) Study; International Report from the 2001/2002 Survey. Copenhagen: WHO Regional Office for Europe.

15. Bronfenbrenner U (1986) Ecology of the family as a context for human development: research perspectives. Dev Psychol 22, 723-742.

16. Bronfenbrenner U \& Morris PA (1988) The ecology of human developmental processes. In The Handbook of Child Psychology, pp. 993-1027 [W Damen and N Eisenberg, editors]. New York: John Wiley \& Sons. 
17. Kremers SP, de Bruijn GJ, Visscher TL et al. (2006) Environmental influences on energy balance-related behaviors: a dual-process view. Int J Behav Nutr Phys Act 3, 9.

18. Swinburn B, Egger G \& Raza F (1999) Dissecting obesogenic environments: the development and application of a framework for identifying and prioritizing environmental interventions for obesity. Prev Med 29, 563-570.

19. Zive MM, Frank-Spohrer GC, Sallis JF et al. (1998) Determinants of dietary intake in a sample of white and Mexican-American children. J Am Diet Assoc 98, 1282-1289.

20. Spurrier NJ, Magarey AA, Golley R et al. (2008) Relationships between the home environment and physical activity and dietary patterns of preschool children: a cross-sectional study. Int J Behav Nutr Phys Act 5, 31.

21. Pearson N, Biddle SJ \& Gorely T (2009) Family correlates of fruit and vegetable consumption in children and adolescents: a systematic review. Public Health Nutr 12, 267-283.

22. Rasmussen M, Krolner R, Klepp KI et al. (2006) Determinants of fruit and vegetable consumption among children and adolescents: a review of the literature. Part I: Quantitative studies. Int J Behav Nutr Phys Act 3, 22.

23. van der Horst K, Oenema A, Ferreira I et al. (2007) A systematic review of environmental correlates of obesityrelated dietary behaviors in youth. Health Educ Res 22, 203-226.

24. Timperio A, Ball K, Roberts R et al. (2008) Children's fruit and vegetable intake: associations with the neighbourhood food environment. Prev Med 46, 331-335.

25. Skidmore P, Welch A, van Sluijs E et al. (2010) Impact of neighbourhood food environment on food consumption in children aged 9-10 years in the UK SPEEDY (Sport, Physical Activity and Eating behaviour: Environmental Determinants in Young people) study. Public Health Nutr 13, 1022-1030.

26. Ding D, Sallis JF, Norman GJ et al. (2011) Community food environment, home food environment, and fruit and vegetable intake of children and adolescents. J Nutr Educ Behav (Epublication ahead of print version).

27. Brug J, Kremers SP, Lenthe F et al. (2008) Environmental determinants of healthy eating: in need of theory and evidence. Proc Nutr Soc 67, 307-316.

28. Bogers RP, Van Assema P, Kester AD et al. (2004) Reproducibility, validity, and responsiveness to change of a short questionnaire for measuring fruit and vegetable intake. Am J Epidemiol 159, 900-909.

29. Haraldsdottir J, Thorsdottir I, de Almeida MD et al. (2005) Validity and reproducibility of a precoded questionnaire to assess fruit and vegetable intake in European 11- to 12-year-old schoolchildren. Ann Nutr Metab 49, 221-227.

30. Gattshall ML, Shoup JA, Marshall JA et al. (2008) Validation of a survey instrument to assess home environments for physical activity and healthy eating in overweight children. Int J Behav Nutr Phys Act 5, 3.

31. Giskes K, van Lenthe FJ, Kamphuis CB et al. (2009) Household and food shopping environments: do they play a role in socioeconomic inequalities in fruit and vegetable consumption? A multilevel study among Dutch adults. J Epidemiol Community Health 63, 113-120.

32. Kamphuis CB, van Lenthe FJ, Giskes K et al. (2007) Perceived environmental determinants of physical activity and fruit and vegetable consumption among high and low socioeconomic groups in the Netherlands. Health Place 13, 493-503.

33. Cole TJ, Bellizzi MC, Flegal KM et al. (2000) Establishing a standard definition for child overweight and obesity worldwide: international survey. BMJ 320, 1240-1243.

34. Baron RM \& Kenny DA (1986) The moderator-mediator variable distinction in social psychological research: conceptual, and statistical considerations. J Pers Soc Psychol 51, 1173-1182.

35. Kristjansdottir AG, Thorsdottir I, De Bourdeaudhuij I et al. (2006) Determinants of fruit and vegetable intake among 11-year-old schoolchildren in a country of traditionally low fruit and vegetable consumption. Int J Behav Nutr Phys Act 3, 41.

36. Wind M, de Bourdeaudhuij I, te Velde SJ et al. (2006) Correlates of fruit and vegetable consumption among 11-year-old Belgian-Flemish and Dutch schoolchildren. J Nutr Educ Behav 38, 211-221.

37. Reinaerts E, de Nooijer J, Candel M et al. (2007) Explaining school children's fruit and vegetable consumption: the contributions of availability, accessibility, exposure, parental consumption and habit in addition to psychosocial factors. Appetite 48, 248-258.

38. Caldwell EM, Miller Kobayashi M, DuBow WM et al. (2009) Perceived access to fruits and vegetables associated with increased consumption. Public Health Nutr 12, 1743-1750.

39. Lucan SC \& Mitra N (2012) Perceptions of the food environment are associated with fast-food (not fruit-andvegetable) consumption: findings from multi-level models. Int J Public Health 57, 599-608.

40. Zenk SN, Lachance LL, Schulz AJ et al. (2009) Neighborhood retail food environment and fruit and vegetable intake in a multiethnic urban population. Am J Health Promot 23, 255-264.

41. TNO, Netherlands Organisation for Applied Scientific Research (2010) Vijde Landelijke Groeistudie (Fifth National Growth Study). Leiden: TNO.

42. Tak NI, te Velde SJ, de Vries JH et al. (2006) Parent and child reports of fruit and vegetable intakes and related family environmental factors show low levels of agreement. J Hum Nutr Diet 19, 275-285.

43. Reinaerts E, de Nooijer J \& de Vries NK (2007) Parental versus child reporting of fruit and vegetable consumption. Int J Behav Nutr Phys Act 4, 33.

44. Steenhuis IH, Waterlander WE \& de Mul A (2011) Consumer food choices: the role of price and pricing strategies. Public Health Nutr 14, 2220-2226.

45. Waterlander WE, de Mul A, Schuit AJ et al. (2010) Perceptions on the use of pricing strategies to stimulate healthy eating among residents of deprived neighbourhoods: a focus group study. Int J Behav Nutr Phys Act 7, 44. 